Canadian

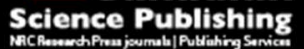

Canadian Journal of Civil Engineering

Revue canadienne de génie civil

\title{
Background to Some of the Seismic Design Provisions of the 2015 National Building Code of Canada
}

\begin{tabular}{|r|l|}
\hline Journal: & Canadian Journal of Civil Engineering \\
\hline Manuscript ID & cjce-2014-0385.R1 \\
\hline Manuscript Type: & Article \\
\hline Date Submitted by the Author: & 15 -Jul-2015 \\
\hline Complete List of Authors: & Humar, Jag; Dept. of Civil and Environmental Engineering \\
\hline Keyword: & $\begin{array}{l}\text { Struct.Eng. \& Constr. Mate, response-earthquake load < Struct. Eng. \& } \\
\text { Constr.Mate, design < type of paper to review }\end{array}$ \\
\hline
\end{tabular}




\title{
Background to Some of the Seismic Design Provisions of the 2015 National Building Code of Canada
}

\author{
Jagmohan Humar \\ Department of Civil and Environmental Engineering \\ Carleton University \\ 1125 Colonel By Drive, Ottawa, ON K1S 5B6, Canada \\ Tel: 6135202600 (5787) \\ Fax: 6135203951 \\ Email: jag.humar@carleton.ca
}

Words including abstract, keywords and reference list: 6949

Tables and Figures: 11 x $250=2750$ 
Abstract: The last version of the National Building Code of Canada was issued in 2010. The next version will be issued in 2015. In the code cycle between 2010 and 2015 significant changes have taken place in the seismic design provision. The main factor that drives these changes is an improved understanding of the seismic hazard across the country. Changes have also been introduced in the site effect factors. The structural design provisions have been appropriately adjusted to respond to changes in the estimates of hazard and the new site effect factors. There are also new provisions related to design in regions of low hazard, buildings with flexible diaphragms, buildings with inclined columns, passive energy dissipation systems, base isolation, rocking foundations, glazing systems, racks, and elevators. Some of the changes are briefly discussed. The main focus of the paper is, however, on the revisions to the structural design provisions.

Key Words: seismic hazard, site effect factors, design response spectrum, low hazard zones, higher mode effect, flexible diaphragms, 


\section{Introduction}

The 2015 National Building Code of Canada will include a number of significant changes in the seismic design provisions. In parallel with the evolution of NBC, changes will be introduced in the referenced material standards, including those on structural concrete, steel, masonry, and wood, to maintain compatibility between the code and the standards.

Design for seismic forces begins with the specification of the seismic hazard at the site. It must be recognized that because of the inherent complexity of the underlying physical phenomenon there is considerable uncertainty associated with specifying the seismic hazard. The steps leading to the determination of the hazard include identifying the source zones, obtaining magnitude recurrence relations, and developing the ground motion prediction equations. Using a methodology based on implementation of the three steps, the 2010 National Building Code of Canada (NBC 2010) provided the design spectral acceleration values at selected periods, a damping of $5 \%$, and a uniform probability of exceedance of $2 \%$ in 50 years for a number of localities across Canada. During the code cycle between 2010 and 2015 considerably more data has become available on the ground motions, which has provided a better understanding of the contributors to the determination of hazard. As a consequence, major changes have taken place in the specified design hazard values across whole of Canada.

The availability of significantly more ground motion data has also led to revisions in the site effect factors, such that the two foundation factors $F_{a}$ and $F_{v}$ specified in NBC 2010 have been replaced by separate factors for each of the following six periods: $0.2,0.5,1.0,2.0,5.0$ and $10.0 \mathrm{~s}$. Site effect factors have also been developed for the peak ground acceleration and peak ground velocity. 
A number of revisions have also been made in the structural design provisions of the code. Some of these provisions reflect the impact of changes in the estimated seismic hazard and site factors. They include specification of the design spectrum, the manner in which the various triggers are specified, short period cap on the design base shear, and higher mode effect factors. A simplified procedure has been introduced for the design of structures in regions of low seismic hazard. Certain new provisions address design issues not previously dealt with, such as, design of buildings with flexible diaphragms, design of buildings having inclined columns, passive energy dissipation, base isolation, design of glazing systems, and design of steel pallet storage racks and elevators. Finally, there are revisions influenced by Canadian and international research, improved understanding of material and structural behaviour, and developments taking place in other international codes. Examples of such changes include: revisions in ductility $\left(R_{d}\right)$ and over-strength $\left(R_{o}\right)$ related modification factors for concrete and masonry, new $R_{d}$ and $R_{o}$ factors for tilt-up construction in reinforced concrete, changes in foundation design provisions, and design provisions for continuous timber construction more than 4 storeys in height.

Brief background is provided to some of the revisions referenced in the preceding paragraph. The main focus of the present article is, however, on the equivalent static load method of design including specification of design spectrum and the higher mode effects.

\section{Seismic hazard}

As in NBC 2010, the seismic hazard in NBC 2015 is specified in terms of 5\% damped spectral acceleration, $S_{a}$, at selected periods, for a uniform probability of exceedance of $2 \%$ in 50 years or a return period of 2475 years. Design spectral accelerations were provided in NBC 2010 for fundamental periods of $0.2,0.5,1.0$, and $2.0 \mathrm{~s}$ for a number of localities throughout Canada. 
For want of sufficient seismological observations, spectral acceleration values for periods longer than 2 s could not be determined with certainty. Based on available information on drop-off gradient of the spectral acceleration with period, the design spectral acceleration at $4 \mathrm{~s}$ and longer was conservatively specified as half of that at $2.0 \mathrm{~s}$. The code also specified the value of peak ground acceleration.

The NBC 2010 seismic hazard values were based on measured ground motion data collected during earthquakes up to the early 1990s. Since then, considerably more data has been obtained. This information along with improved understanding of the seismotectonics has led to improvements in how the source zones are defined, in the ground motion prediction equations (GMPEs), and in the manner in which contributions from different sources are combined.

In NBC 2015 spectral accelerations have been specified for periods of $0.2,0.5,1.0,2.0,5.0$, and $10.0 \mathrm{~s}$. In addition values have been provided for the peak ground acceleration (PGA) as well as the peak ground velocity (PGV). In NBC 2010 the specified values of $S_{a}$ represented the median, implying that there was $50 \%$ chance of the spectral acceleration exceeding the specified value. In NBC 2015, the mean rather than the median is used in the specification of seismic hazard, the mean being closer to the expected value. Mean hazard values typically lie between the $65^{\text {th }}$ and $75^{\text {th }}$ percentiles of the distribution and are thus larger than the median $\left(50^{\text {th }}\right.$ percentile values) hazard values (Adams et al. 2015). Thus there is approximately a 1 in 3 chance that the design values will be exceeded (versus 1 in 2 for a median design value).

\section{Source zones}

In NBC 2010 seismic hazard for the more seismically active regions was determined on the basis of two distinct source zone models: a historically based model, designated as $\mathrm{H}$, and a regional source model named R. For regions of very low seismicity, that is the stable part of 
Canada, a third source zone model termed F model was added. This model represented the floor value of the hazard. For the western region, the Cascadia subduction earthquake zone was considered as a separate zone model. In NBC 2015 a third zone model has been specified for the southeastern Canada. This is in addition to the $\mathrm{H}$ and $\mathrm{R}$ models and is a hybrid between the two. For the western region NBC 2015 uses an updated treatment of the Queen Charlotte fault and the Cascadia subduction zone. In addition, certain other faults in Alaska and Yukon are explicitly included. Detailed background to source zone modelling has been provided by Adams et al (2015) Allen et al (2015) and Rogers et al. (2015).

\section{Ground motion prediction equations}

GMPEs permit the determination of the spectral acceleration ordinates for a given distance to the source and a given magnitude of earthquake; they are thus an essential component of the calculation of seismic hazard. A large volume of new ground motion data has been collected during recent years. This combined with improvements in the methods of analysis has led to the development of many new and improved GMPEs. The selection of GMPEs must be based on the nature of the Earth's crust and the type of earthquake source; in addition, it must consider the scatter in the data (aleatory uncertainty) as well as the differences in the individual GMPEs (epistemic uncertainty) derived on the basis of that data. In view of these considerations, NBC 2015 uses five different GMPEs, each with its central value as well as lower and upper values to account for the epistemic uncertainty. The central value is obtained by considering various published GMPEs that are appropriate for the nature of the crust and the earthquake source in the region under consideration. Details of the selection process have been provided by Atkinson and Adams (2013). 


\section{Combination of the contributions from different sources}

In NBC 2010 the design seismic hazard for the eastern regions was determined by first calculating the probabilistic values of $S_{a}$ obtained for the $\mathrm{H}, \mathrm{R}$ and $\mathrm{F}$ source zones and then adopting the largest of the three values as the design value. For the western region, the largest of four different estimates, probabilistic values for H, R, and F zones, and deterministic value for the Cascadia subduction zone, was taken as the design value. In NBC 2015 the contributions from all sources are combined probabilistically, which is a superior method and is used in most modern seismic hazard models. Combining Cascadia subduction zone in a probabilistic rather than deterministic manner increases the hazard in cities that are affected by Cascadia. Additional details can be found in a recent paper by Adams et al (2015). As stated earlier, in NBC 2010 the hazard values for each source represented the median, while in NBC 2015 it is the mean.

\section{Impact on seismic hazard}

The various factors that contribute to the differences in seismic hazard between NBC 2010 and NBC 2015 have been outlined in the previous paragraphs. The most important among these factors is the influence of the GMPEs used in the calculations. In addition, for the western regions the probabilistic treatment of Cascadia subduction zone has strongly affected the hazard estimates in regions influenced by that zone. Also, the regions close to the faults that are now explicitly included have experienced a significant increase in the hazard. Overall, in the eastern regions, estimates of long-period hazard have increased while the estimates of short-period hazards have decreased. In the west the long period hazard has increased significantly for regions affected by Cascadia subduction zone. Also, regions in the vicinity of recognized faults have experienced large increases in hazard. 
Figure 1 compares the 2010 and 2015 uniform hazard spectra (UHS) for 4 cities: Victoria, Vancouver, Toronto, and Montreal. All spectra have been plotted for Class C site, which is the reference site used for the specification of hazard in the code. The 2010 spectra are plotted only up to a period of $4 \mathrm{~s}$. Figure 1 shows that the hazard in Victoria has increased for entire range of periods. Vancouver sees a decrease in hazard for short periods and marked increase for long periods. The long-period hazard in both cities has increased because of the probabilistic combination of the contribution from Cascadia subduction zone. For Toronto and Montreal the hazard has not changed much, although there is an increase for long periods, chiefly due to the GMPEs used. However, the absolute value of the long period hazard for these cities is comparatively low.

\section{Site effect factors}

It is well known that the characteristics of the underlying soil have a profound effect on the amplitude of seismic waves arriving at the surface. The NBC 2005 and NBC 2010 specified five different soil categories from Class A, hard rock, to Class E, soft soil. Another soil class F was used to cover liquefiable soils and sensitive, organic and highly plastic clays. Classification of soils into categories A to E was based on the average shear wave velocity in the top 30 meters of soil below the bottom of spread footing, mat foundation, or pile cap. Energy-corrected standard penetration resistance or undrained shear strength could be used in lieu of the shear wave velocity. The NBC 2005 provisions on the classification of soils were adopted for NBC 2015.

In NBC 2015, as in NBC 2010 and NBC 2005, Soil Class C is treated as the reference soil condition. This means that for such soils the $S_{a}$ values specified in the code could be used in design without any modification. For soils of the other classes, the code values must be 
multiplied by a site effect factor before being used in design. The site effect factor depends on the nature of soil, and the period and intensity of earthquake shaking. NBC 2010 specified two different factors: factor $F_{a}$ applicable in the short period range, and factor $F_{v}$ in the long period range. Values of $F_{a}$ and $F_{v}$ were specified for each of the 5 soil categories, A to E, and 5 different earthquake intensities. In the short period the intensity was measured by the spectral acceleration at a period of $0.2 \mathrm{~s}$, while in the long period range it was measured by the spectral acceleration at a period of $1.0 \mathrm{~s}$. A site-specific evaluation was required for soils belonging to Class $\mathrm{F}$. Background to the site factors in NBC 2005 and 2010 is provided by Finn and Wightman (2003).

Since the publication of NBCC 2010, far more ground motion data have become available. Seismologists have developed new methodologies that use this much larger database to provide GMPEs in which the site characteristic measured by $V_{S 30}$ serves as a predictor variable to obtain estimates of the site factors. The site factors in NBC 2015 are specified for 6 different periods: $0.2,0.5,1.0,2.0,5.0$ and $10.0 \mathrm{~s}$. The $V_{S 30}$ values that define the boundaries between the various classes of soil are: between A and B $1500 \mathrm{~m} / \mathrm{s}$, between B and C $760 \mathrm{~m} / \mathrm{s}$, between C and D 360 $\mathrm{m} / \mathrm{s}$, and between $\mathrm{D}$ and $\mathrm{E} 180 \mathrm{~m} / \mathrm{s}$. The $V_{S 30}$ values used to determine the factors for soils of Class A, B, C, D, and E are 1600, 1100, 450, 250 and $115 \mathrm{~m} / \mathrm{s}$, respectively. The resulting site factors, $F(T)$, are shown in Table 1. Factors $F(T)$ depend on a reference peak ground acceleration PGA $_{\text {ref }}$ which serves as a measure of the intensity. For locations in the east, and for a given sustained shaking, ground motions have higher amplitudes for PGA than in the west. However these amplitudes sometimes arise from small earthquakes with short duration of shaking and hence have low damage potential, as their ground displacements are very small. In the context of soil amplification and deamplification the direct use of PGA would give $F(T)$ values with larger non-linear deamplification effects in the east than appropriate for their sustained level of shaking. 
Accordingly, in the computation of $F(T), \mathrm{PGA}_{\text {ref }}$ is used instead of PGA, where $\mathrm{PGA}_{\text {ref }}=$ $0.8 \times$ PGA when $S_{a}(0.2) / \mathrm{PGA}$ is less than 2.0 , but is equal to PGA otherwise. A few localities in the west will also be affected by this provision. The design spectral acceleration is denoted by $S$ and is given by $S(T)=F(T) S_{a}(T)$.

The NBC 2010 incorporated several triggers which direct the designer to select one of two alternative design procedures. The triggers were generally specified in terms of $I_{E} F_{a} S_{a}(0.2)$ for the short period hazard and $I_{E} F_{v} S_{a}(1.0)$ for the medium-period hazard. As an example, the code allowed the use of equivalent static load method of design whenever $I_{E} F_{a} S_{a}(0.2)$ was less than 0.35 . In NBCC 2015, $F_{a}$ will be defined as being equal to $F(0.2)$ and $F_{v}$ will be defined as being equal to $F(1.0)$.

\section{Specification of seismic hazard}

As in NBCC 2010, the seismic hazard is represented in NBCC 2015 by a uniform hazard spectrum (UHS) for the given site. The UHS is comprised of straight lines joining code-specified values of the spectral accelerations at a series of periods. Figure 1 shows the uniform hazard spectra for some selected sites. As stated earlier, NBCC 2015 provides spectral acceleration values for periods of $0.2,0.5,1.0,2.0,5.0$, and $10.0 \mathrm{~s}$. Spectral values at periods of $0.05,0.1$ and $0.3 \mathrm{~s}$ have also been determined and will be available from the Geological Survey of Canada.

At most sites the spectral acceleration decreases continuously from its value at $0.2 \mathrm{~s}$ to the peak ground acceleration at a period equal to zero. However, in the UHS an upper plateau is defined at $T=0.2 \mathrm{~s}$, so that for $T<0.2 \mathrm{~s}$ the spectral acceleration is equal to $S_{a}(0.2)$. This is because it is not considered good practice to design on the basis of a spectrum in which $S$ increases with the period. With yielding of the structure, expected during an earthquake, its 
period becomes longer and if that causes the structure to migrate into a region of the spectrum in which the spectral value is greater, the structure will attract greater force than it was designed for.

For a few locations $S_{a}(0.1)$ is greater than $S_{a}(0.2)$. Such is the case for Niagara Falls, Toronto, and Kingston (Figure 2a); and for Montreal, Ottawa, and Trois-Rivières (Figure 2b). In cases where $S_{a}(0.1)$ is larger than $S_{a}(0.2)$, a plateau at $0.2 \mathrm{~s}$ implies that the design base shear in a structure with a period of $0.1 \mathrm{~s}$ will be underestimated. The plots in Figures $2 \mathrm{a}$ and $\mathrm{b}$ also indicate the ratio $S_{a}(0.2) / S_{a}(0.1)$. The lowest value of this ratio is around 0.80 , so that the underestimate of base shear would be no greater than $20 \%$, and significantly less in most cases. Considering that short-period structures have significant reserve strength, and as explained later, the code permits a judgement based reduction in the design force for such structures, the upper plateau at $0.2 \mathrm{~s}$ is maintained.

In several cases $S(0.5)$ is larger than $S(0.2)$. Such is the case for Class D and E spectra for Victoria (Figure 2c) and Vancouver (Figure 2d). There exist other similar cases, particularly for the softer soils. As stated earlier, it is not considered a good practice to design on the basis of a spectrum in which the $S$ value increases with period. This was recognized in NBCC 2010 when reviewing the spectra for Class F soils. It is recommended that in such cases the upper plateau should be moved to the highest peak in the spectrum. Such adjustment to the spectrum is shown by dashed lines in Figure 2c and d for Class D and E spectra for Victoria and Vancouver.

The adjustment to the spectra referred to in the preceding paragraph and illustrated in Figures $2 \mathrm{c}$ and $\mathrm{d}$ is achieved by using the following specification in the code: 


\section{Site Properties}

The design spectral acceleration values of $S(T)$ shall be determined as follows, using linear interpolation for intermediate values of $T$ :

$$
\begin{aligned}
S(T) & =F(0.2) S_{a}(0.2) \text { or } F(0.5) S_{a}(0.5) \text { whichever is larger for } T \leq 0.2 \mathrm{~s} \\
& =F(0.5) S_{a}(0.5) \text { for } T=0.5 \mathrm{~s} \\
& =F(1.0) S_{a}(1.0) \text { for } T=1.0 \mathrm{~s} \\
& =F(2.0) S_{a}(2.0) \text { for } T=2.0 \mathrm{~s} \\
& =F(5.0) S_{a}(5.0) \text { for } T=5.0 \mathrm{~s} \\
& =F(10.0) S_{a}(10.0) \text { for } T \geq 10.0 \mathrm{~s}
\end{aligned}
$$

\section{Short period cut-off}

Recognizing that short period structures usually have more reserve strength than accounted for, undergo small displacement, and have performed relatively well during the past earthquakes, NBC 2015 allows such structures to be designed for $2 / 3$ the calculated base shear provided the structure has been detailed to have at least a limited amount of ductility. This is achieved by specifying a short period cap at $2 \times S(0.2) / 3$ on the UHS. However, in some cases the spectral shape is so flat that the cap extends to periods considerably longer than $0.5 \mathrm{~s}$, the period range for which such cap was not intended. To avoid such a situation NBC 2015 provides that the cap be $2 \times S(0.2) / 3$ or $S(0.5)$, whichever is greater. This can be appreciated by referring to Figure 3 a for Tofino and Queen Charlotte City, Figure 3b for Victoria, Nanaimo, and Campbell River, Figure 3c for Chilliwack, Prince George and Vancouver, and Figure 3d for Charlotte Town, Halifax, and St. John's.

\section{Higher mode effects}

The code specifies a method of determining the equivalent static design base shear that is based on the assumption that the structure responds in its first mode. The base shear is thus obtained from the estimated fundamental period $T_{a}$ and the site-adjusted UHS for the location of 
the structure. The shear so obtained is multiplied by a factor $M_{v}$ to account for the effect of higher modes to obtain a better estimate of the elastic base shear, giving

$$
V_{e}=S\left(T_{a}\right) M_{v} W
$$

where $S(T)=F\left(T_{a}\right) \mathrm{S}_{a}\left(T_{a}\right)$ is the design spectral acceleration in units of gravity, $S_{a}\left(T_{a}\right)$ is obtained from the UHS for the site and $W$ is the seismic weight, equal to the dead load plus a portion of the live load. The elastic shear $V_{e}$ is divided by a ductility related modification factor $R_{d}$ and an overstrength related modification factor $R_{o}$ to obtain the design base shear. Factor $R_{d}$ reflects the capability of a structure to dissipate energy through inelastic behaviour and is a measure of its ductility capacity. Factor $R_{o}$ accounts for the dependable portion of reserve strength in a structure designed according to the NBCC provisions. The rationale for the use of these two factors and their values for various structural systems are given by Mitchell et al. (2003)

For certain important buildings the adjusted base shear is multiplied by an importance factor $I_{E}$. Thus the design base shear is given by

$$
V=\frac{S\left(T_{a}\right) M_{v} I_{E} W}{R_{d} R_{O}}
$$

The higher mode adjustments factor depends on the period of the building, shape of the design spectrum, and the characteristics of the structure. The last of these include the spread between the values of the fundamental and higher modes, and the modal participation factors. A steeper spectral shape attracts greater participation from the higher modes. Shear walls attract greatest higher mode participation because they show the largest spread between period values and the largest participation factors for the upper modes. Shear wall structures are followed by braced frame structures and moment frame structures, in that order. Some of these characteristics can be observed from Figure 4 which shows the UHS for Vancouver and Toronto. For 
facilitating comparison the spectra have been normalized by the spectral value at $1.0 \mathrm{~s}$. Also shown in that figure are vertical lines corresponding to the first and second mode periods of a structure in which the seismic force resisting system (SFRS) consists of moment-resisting frames, a structure in which the SFRS is comprised of braced frames, and a structure in which the SFRS is comprised of shear walls. All of the structures are assumed to have $T_{a}=1.0 \mathrm{~s}$. When compared to the frame structure, the second mode period of the wall structure falls in the higher spectral region of the UHS. The second mode for braced frame lies between those for frame structure and wall structure. The spectrum for Toronto is much steeper than that for Vancouver; consequently, the second mode spectral accelerations for Toronto are significantly higher than those for Vancouver.

The base shear is distributed along the height of the buildings by first applying a lateral force $F_{t}$ at the top of the building to account for the effect of higher modes. Force $F_{t}$ is given by

$$
\begin{array}{ll}
F_{t}=0 & T_{a} \leq 0.7 \\
F_{t}=0.07 T_{a} V & 0.7<T_{a}<3.6 \\
F_{t}=0.25 V & T_{a} \geq 3.6
\end{array}
$$

The remaining portion of the base shear is distributed according to a shape that is representative of the first mode, giving

$$
F_{x}=\left(V-F_{t}\right) \frac{W_{x} h_{x}}{\sum_{i=1}^{n} W_{i} h_{i}}
$$

where $F_{x}$ is the lateral force at level $x, W_{x}$ is the seismic weight at level $x, h_{x}$ is the height above base to the level $x$, and $n$ is the number of floors. Empirical equations 3 and 4 are identical in NBC 2010 and NBC 2015. The overturning moments computed from forces $F_{x}$ obtained using Equations 3 and 4 overestimate the true overturning moments. This is because, while the shear $V$, and hence $F_{x}$, account for the participation of higher modes, the overturning moments produced 
by such modes is comparatively small. The code therefore specifies base overturning moment reduction factor $J$ and similar factor $J_{\mathrm{x}}$ at each level $x$. The expressions to determine $J_{x}$ are identical in NBC 2010 and NBC 2015. Thus, $J_{x}=1.0$ over the top $40 \%$ of the building height, and varies linearly from this value to the $J$ value at the base.

The methodology used to determine the $M_{v}$ and $J$ factors has been described by Humar and Mahgoub (2003). Factor $M_{v}$ is given by

$$
M_{V}=\frac{\sqrt{\sum\left[S\left(T_{i}\right) W_{i}\right]^{2}}}{S\left(T_{a}\right) W}
$$

where $S\left(T_{i}\right)$ is the site-adjusted spectral acceleration corresponding to the $i$ th modal period, $W_{i}$ is the corresponding modal weight, and $W$ is the total weight of the building. The summation in Equation 5 is carried out over all modes included in the computation. The numerator on the right hand side of that equation is the base shear obtained from a modal response spectrum analysis, while the denominator is the base shear assuming that the entire weight participates in the first mode.

The shear $M_{v} S\left(T_{a}\right) W$ is distributed across the height according to Equations 3 and 4 to obtain the lateral forces $F_{x}$. These forces are used to calculate the base overturning moment $M_{b c}$ and the storey level moments $M_{x c}$. The corresponding moments obtained from a response spectral analysis are $M_{b e}$ and $M_{x e}$. The overturning moment reduction factors are then given by

$$
J=\frac{M_{b e}}{M_{b c}} \quad J_{x}=\frac{M_{x e}}{M_{x c}}
$$

It is evident from Equations 5 and 6 that for a given spectrum the shear and moment adjustment factors depend only on the modal periods and modal weights. 
The higher mode adjustment factors are determined here separately for the three major categories of structures, moment frame structures, braced frame structures, and shear wall structures. Representative ten-storey structures are used for this purpose; they have been described in the paper by Humar and Mahgoub (2003). The modal periods and modal weights for the structures are shown in Table 2.

The spectral shape, or how steep is the spectrum, can be determined by considering the spectral ratio $S(0.2) / S(5.0)$. For the locations included in the climatic data table of the code, this ratio for Class $\mathrm{C}$ soil ranges from 3.8 to 51.3. Values of the spectral ratio for some selected cities are shown in Tables 3 and 4. In 2010 NBCC the spectral shapes for cities in the geographical east were generally steeper than those in the geographical west. Thus, the 2010 NBCC ratio $S_{a}(0.2) / S_{a}(2.0)=8$ was used as the demarcation between the geographical west and east and two sets of $M_{v}$ and $\mathrm{J}$ factors were specified, one set for the west and another set for east. The seismological data on which the provisions of NBC 2015 are based show that the spectral shape does not depend on the geographical location but is governed by the contributions of nearby earthquakes relative to distant larger earthquakes. The spectra for some cities in the west are, in fact, quite steep. This will be evident from the data presented in Tables 3 and 4, which show that ratio $S_{a}(0.2) / S_{a}(5.0)$ for some cities in the western region is, in fact, greater than that for many cities in the eastern region.

Factors $M_{v}$ and $J$ are derived here for specific values of the spectral ratio, namely 5, 20, 40 and 65. This covers almost the entire expected range of the spectral ratios. The database of UHS used for the derivation comprises Class C uniform hazard spectra for 27 cities, selected from those listed in Table 3, and Class A to E spectra for Victoria, Vancouver, Calgary, Montreal, Toronto, and Fredericton, giving a total of 57 spectra. 
The results for $M_{v}$ and $J$ values are presented in Figure 5 as scatter diagrams. Also shown are piece-wise linear representations of these values. Separate curves are provided for $\mathrm{T}=0.5$, 1.0, 2.0, and $5.0 \mathrm{~s}$, except that when the $M_{v}$ value is less than 1 for the entire range of the ratio $S(0.2) / S(5.0)$, the corresponding curve is not shown. It is apparent from Figure 5 that for a given structural type the spectral ratio and the fundamental period are the two parameters that most influence the response.

The code provisions on $M_{v}$ and $J$ factors are derived from the straight line representations in Figure 5 and are shown in Table 5. In these provisions the $M_{V}$ factor is specified as being no less than 1. This is in keeping with similar provision in NBC 2010, is on the conservative side, and is justified by the fact that as the number of storeys approaches $1, M_{V}$ value will approach 1 . Similarly, $J$ is taken as no larger than 1 . The code specifies that for moment resisting frames and braced frames the design base shear be taken as not less than that for a period of $2.0 \mathrm{~s}$. Accordingly $M_{v}$ and $J$ values are not specified for such structures for periods greater than $2.0 \mathrm{~s}$. For shear wall structures the minimum design base shear specified in the code is that corresponding to a period of $4.0 \mathrm{~s}$. The product $M_{v} S$ at $4 \mathrm{~s}$ may be obtained by interpolation between its values for 2 and 5 seconds. The coupled walls respond to earthquake motion in a manner that is somewhere between those of moment frames and shear walls. In most practical cases the behaviour is closer to that of a moment frames, except that the likelihood of inelastic demand being concentrated in a storey is smaller. Thus the $M_{v}$ and $J$ factors for coupled walls are similar to those for moment frame, but the minimum design shear is that corresponding to a period of $4.0 \mathrm{~s}$ as in the case of shear wall structures. 


\section{Example}

An example is provided here to illustrate the derivation of $M_{V} S$ based on the specifications in NBC 2015.

Consider a shear wall structure having a fundamental period of $1.5 \mathrm{~s}$. located on Class D soil in Toronto. The uniform hazard spectral accelerations for Toronto (for Site Class C) specified in the Table of Climatic Data are: PGA $=0.16, \mathrm{~S}_{\mathrm{a}}(0.2)=0.249, \mathrm{~S}_{\mathrm{a}}(0.5)=0.126, \mathrm{~S}_{\mathrm{a}}(1.0)=0.063$, $\mathrm{S}_{\mathrm{a}}(2.0)=0.029$, and $\mathrm{S}_{\mathrm{a}}(5.0)=0.007$, all in units of $\mathrm{g}$.

The ratio $S_{\mathrm{a}}(0.2) / \mathrm{PGA}=0.249 / 0.160=1.56$. This ratio is less than 2.0 , hence, $\mathrm{PGA}_{\text {ref }}=0.8$ $\times \mathrm{PGA}=0.128$. The foundation factors for PGA $\mathrm{A}_{\text {ref }}$ values of $0.1 \mathrm{~g}$ and $0.2 \mathrm{~g}$ and for Class D are specified in the code and are shown in Table 1. The $F(T)$ values corresponding to $\mathrm{PGA}_{\text {ref }}=$ 0.128 , obtained by interpolating between the values for $0.1 \mathrm{~g}$ and $0.2 \mathrm{~g}$, are: $1.1980 \mathrm{for}$ a period of $0.2 \mathrm{~s}, 1.5052$ for a period of $1.0 \mathrm{~s}, 1.5336$ for a period of $2.0 \mathrm{~s}$ and 1.5520 for a period of $5.0 \mathrm{~s}$.

The spectral ratio for Toronto is given by

$$
S_{r}=\frac{\mathrm{S}(0.2)}{\mathrm{S}(5.0)}=\frac{1.1980 \times 0.249}{1.5520 \times 0.007}=27.46
$$

The spectral accelerations for Toronto at periods of 1.0 and $2.0 \mathrm{~s}$ and Class D soil are determined as follows:

$$
\begin{aligned}
& S(1.0)=1.5052 \times 0.063=0.0948 \\
& S(2.0)=1.5336 \times 0.029=0.0445
\end{aligned}
$$

The $M_{v}$ values for periods of $1.0 \mathrm{~s}$ and $2.0 \mathrm{~s}$ corresponding to $S_{r}=27.46$ are obtained from the data in Table 5 by interpolating between $S_{r}=20$ and 40 as shown in the following:

For spectral ratio of 20.0: $M_{v}(1.0)=1.00$ and $M_{v}(2.0)=1.18$

For spectral ratio of 40.0: $M_{v}(1.0)=1.19$ and $M_{v}(2.0)=1.75$

Interpolation gives for $S_{r}=27.46: M_{v}(1.0)=1.067$ and $M_{v}(2.0)=1.393$ 
Next $M_{\nu} S$ is interpolated between periods of 1.0 and $2.0 \mathrm{~s}$.

$M_{v} S$ at $1.0 \mathrm{~s}=1.067 \times 0.0948=0.1020$

$M_{\nu} S$ at $2.0 \mathrm{~s}=1.391 \times 0.0445=0.0619$

$M_{\nu} S$ at $1.5=0.0816$

The $J$ values for periods of $1.0 \mathrm{~s}$ and $2.0 \mathrm{~s}$ corresponding to $S_{r}=27.5$ are obtained from the data in Table 5 by interpolation as shown in the following:

For spectral ratio of 20.0: $J(1.0)=0.80$ and $J(2.0)=0.60$

For spectral ratio of 40.0: $J(1.0)=0.63$ and $J(2.0)=0.46$

Interpolation gives for $S_{r}=27.46: J(1.0)=0.737$ and $J(2.0)=0.548$

Next $J$ is interpolated between periods of 1.0 and $2.0 \mathrm{~s}$

$J$ at $1.5=0.5 \times(0.737+0.548)=0.642$

\section{Low-hazard Zones}

A large portion of Canada's land mass consists of tectonically stable region with low seismic activity. The central part of Canada including the prairies falls in this region. However, in spite of the low seismic activity, large earthquakes can occur in the region. Experiences in stable tectonic regions around the world confirm this. For example, the 2012 Christchurch (New Zealand) Earthquake, the 1995 Kobe (Japan) Earthquake, and the 1989 Newcastle (Australia) Earthquake all occurred in areas of moderate to low seismic activity. Although moderate in intensity, these earthquakes were located close to an urban centre and caused considerable damage. Considering that the occurrence of severe earthquakes was quite rare and hence the earthquake hazard was low in the stable regions of Canada, the NBC 2010 exempted such areas, specifically those where $F_{a} S_{a}(0.2)$ was less than 0.12 , from the requirements of seismic design. With the revisions in the values of seismic hazard for NBC 2015 some locations in the eastern 
part of Canada will also fall below this limit, and if the NBC 2010 specification were to be adopted, will not require seismic design.

In view of the experience in other stable areas of the world and the fact that eastern region of Canada has seen considerable seismic activity, NBC 2015 requires that seismic design is carried out in all regions of Canada. However, the code provides a much simplified design procedure for areas of low hazard. The low hazard areas are defined as those where $I_{E} F_{s} S_{a}(0.2)$ is less than 0.16 and $\mathrm{I}_{\mathrm{E}} \mathrm{F}_{\mathrm{s}} \mathrm{S}_{\mathrm{a}}(2.0)$ is less than 0.03 . The trigger values of 0.16 and 0.03 are based on judgment. The $0.2 \mathrm{~s}$ trigger of 0.16 implies that all buildings in a low hazard zone, such as Winnipeg, with the exception of important or post-disaster buildings located on poor soil, could be designed using the simplified procedure. The trigger also exempts from full design buildings in some eastern locations where the hazard is low, but still noticeable. Buildings in Calgary will need full design since both the 0.16 and 0.03 triggers are exceeded. There are regions in $\mathrm{BC}$ where the spectral curve is quite flat and the 0.2 second value is quite low but the 2 second value is higher than 0.03 . Detailed design will be required for such buildings. Many of these buildings used to be in regions where the 0.2 second value was much higher according to NBC 2010 and the code then required that they be fully designed for earthquakes; without the limit of 2 second 0.03 value they would have been now allowed to be designed using the simple approach.

The foundation factor $F_{s}$, which substitutes for $F_{a}$, does not require the measurement of shear wave velocity and is given by

$$
\begin{aligned}
F_{S} & =1.0 \text { for rock sites or when } N_{60}>50 \text { or } S_{u} \text { is }>100 \mathrm{kPa}, \\
& =1.6 \text { when } 15 \leq N_{60} \leq 50 \text { or } 50 \mathrm{kPa} \leq S_{u} \leq 100 \mathrm{kPa}, \\
& =2.8 \text { for all other cases, }
\end{aligned}
$$


where $N_{60}$ is the average energy corrected standard penetration resistance of the soil and $S_{u}$ is the average undrained shear strength for the top $30 \mathrm{~m}$ below the footing, pile cap, or mat foundation. Values of $F_{s}$ are selected from Table 1, being the most conservative estimates for periods between 0.2 and $1.0 \mathrm{~s}$. Thus the highest value of $F_{s}$ for a period of $0.2 \mathrm{~s}$ is for a site of Class $\mathrm{E}$ and is 1.64 , while the highest value of $F_{s}$ for a period of $1.0 \mathrm{~s}$ is 2.81 , again for a Class E site. The trigger value of $I_{E} F_{S} S_{a}(0.2)$ beyond which detailed design would be required has been raised from 0.12 to 0.16 , since even the structures below the trigger will be designed for earthquake forces, although using a simplified procedure. On the other hand, the trigger now includes the importance factor to ensure that important structures perform better.

The minimum design earthquake base shear $V_{s}$ is calculated from

$$
V_{s}=F_{s} S_{a}\left(T_{a}\right) I_{E} W_{t} / R_{s}
$$

Equation 7 is similar to Equation 2, except that there is no higher mode effect factor and the factors $R_{d}$ and $R_{o}$ have been replaced by a single factor $R_{s}$. Factor $R_{s}$ is taken as 1.5 being equal to that allowed for structural systems not designed to meet the earthquake requirements. However, $R_{s}$ must be taken as 1 for structures having a weak storey or built of unreinforced masonry. Distribution of the shear along the height is similar to that in the detailed design procedure.

The code specifies that the design shear $V_{s}$ should be no less than $F_{s} S_{a}(1.0) I_{E} W_{t} / R_{s .}$ This limit is conservative in comparison to that prescribed in the detailed design procedure. Since for most cases $M_{V}$ value is 1 for periods less than or equal to 1 as shown in Table 5, $M_{V}$ factor is not included in Equation 7. There is also an upper limit on the design shear equal to $F_{s} S_{a}(0.5) I_{E} W_{t} / R_{s}$ provided $R_{s}$ is equal to or greater than 1.5 .

The design procedure specified for low-hazard zones is a much simplified and self-contained version of the detailed procedure. The specification of the simple procedure will appear toward the beginning of 
the code requirements, so that if the site meets the definition of a low-hazard zone, the designer would not be required to review the steps involved in the detailed procedure. Procedures for considering the effect of torsion as well as the specifications related to displacement limits are similar to those in the equivalent static design method of the detailed procedure.

\section{Buildings with flexible diaphragms}

Single storey buildings with large foot prints, such as those used for commercial, educational, or institutional purposes, often have a flexible steel deck or wood panel diaphragm. The response of such buildings to seismic loads is strongly affected by the flexibility of the roof diaphragm. Diaphragm flexibility alters the manner in which the inertia forces, shears, and bending moments are distributed along the length of the diaphragm. In addition, it causes a significant increase in the ductility demand on the lateral load resisting system that is expected to be strained into the inelastic range under the design earthquake. NBC 2015 includes design specifications that account for the effect of diaphragm flexibility on the period of the building and the increased ductility demand on the lateral force resisting system These specifications are based on several research studies related to the seismic response of buildings with flexible diaphragms (Humar and Popovski, 2013, Tremblay et al 2000, Tremblay and Stiemer 1996, Trudel-Languedoc et al 2012).

Flexibility of the diaphragms elongates the period of a building, so the empirical formulas for determining the period should account for it. Based on modal analysis of a large number of prototype buildings with flexible diaphragm the following empirical formulas for the fundamental period have been developed for NBC 2015.

$$
\begin{array}{ll}
T_{a}=0.05 h_{n}^{3 / 4}+0.004 L & \text { for shear walls } \\
T_{a}=0.035 h_{n}+0.004 L & \text { for steel moment frames and steel braced frames }
\end{array}
$$


where $L$ is the span of the diaphragm in meters, between adjacent vertical elements of the SFRS. In case of multiple spans, the shortest span is to be used. The term containing $L$ accounts for the flexibility of the diaphragm. As an alternative to the empirical formulas, the period may be determined by the method of mechanics, but the $T_{a}$ so determined should not exceed 1.5 times the empirical period. As in the case of other structures, the upper limit on the analytical period for buildings with flexible diaphragm is meant to account for the possibility that the model used to calculate the period may not have considered all of the structural and non-structural elements that could contribute to the stiffness.

Studies have shown that in single storey buildings with flexible diaphragm the flexibility of the diaphragm generally causes an increase in the ductility demand on the SFRS. Consequently, to keep the ductility demand unchanged the ductility related force modification factor must be assigned a value that is smaller than the ductility capacity $R_{d}$. The revised force modification factor is denoted here by $\widetilde{R}_{d}$.

To estimate the increase in ductility demand Humar and Popovski (2013) carried out time history analyses on 65 single-storey buildings with flexible steel deck diaphragm designed by Tremblay and Stiemer (1996) for their response to El Centro 1941 ground motion as well as to 5 other spectrum compatible ground motions. Based on the results of their study, Humar and Popovski suggested an equation relating the force reduction factor to the ductility capacity of the lateral load resisting system and the drift ratio $r$. The drift ratio, $r$ is defined as the ratio of the maximum horizontal deformation of the diaphragm along its length $\left(\Delta_{\mathrm{D}}\right)$ to the average inter-story drift of the lateral load resisting elements supporting the diaphragm $\left(\Delta_{\mathrm{B}}\right)$ produced by the action of uniform static lateral load acting along the length of the diaphragm. 
The proposed relationship between $\widetilde{R}_{d}$ and $R_{d}$ is as follows:

[9]

$$
\begin{aligned}
& \widetilde{R}_{d}=\kappa R_{d} \\
& \kappa=-0.5 r+1.5 \\
& 1 \geq \kappa \geq 0.64 \text { for } \mu=2 \\
& 1 \geq \kappa \geq 0.5 \quad \text { for } \mu=3 \\
& 1 \geq \kappa \geq 0.4 \quad \text { for } \mu=4
\end{aligned}
$$

Figure 6 shows the response data obtained from the time history analyses of the 65 buildings for ground motions compatible with the UHS for Vancouver. Also shown are the straight line relationships given by Equations 9 and 10 .

For NBC 2015 a simple relationship between $\widetilde{R}_{d}$ and the drift ratio $r$ was developed. Consider a system that consists of two springs in series with a mass attached to the end of the second spring. The first spring represents the lateral force resisting system while the second represents the diaphragm. When the system remains elastic the dynamic force imposed on the mass by earthquake motion is $V_{e}$. Assuming a ductility related force modification factor $\widetilde{R}_{d}$ and overtstrength related modification factor $R_{o}$, the design force is determined as $V=V_{e} /\left(\widetilde{R}_{d} R_{o}\right)$. The elastic displacement is given by

$$
\Delta_{e}=\frac{V_{e}}{K_{B}}+\frac{V_{e}}{K_{D}}=\widetilde{R}_{d} R_{o}\left(\frac{V}{K_{B}}+\frac{V}{K_{D}}\right)=\widetilde{R}_{d} R_{o}\left(\Delta_{B}+\Delta_{D}\right)
$$

When the diaphragm remains elastic while the SFRS is strained into the inelastic range, the acceptable elasto-plastic displacement is determined from

$$
\Delta_{i}=R_{o} \Delta_{D}+R_{o} R_{d} \Delta_{B}
$$

Assuming that the equal displacement concept holds good, that is $\Delta_{e}=\Delta_{i}$, a relationship between $\widetilde{R}_{d}$ and the ductility capacity $R_{d}$ is obtained from Equations 11 and 12 . 


$$
\begin{aligned}
& \widetilde{R}_{d}=\frac{R_{d} \Delta_{B}+\Delta_{D}}{\Delta_{B}+\Delta_{D}}=\frac{R_{d}+r}{1+r} \\
& \kappa=\frac{R_{d}+r}{R_{d}(1+r)}
\end{aligned}
$$

Equation 13 has also been plotted in Figure 7. It provides almost a lower bound to the dynamic analyses data. The NBC 2015 provisions on the design of buildings with flexible diaphragm are based on Equation 13.

Equation 13 shows that $\kappa$ is less than 1 implying that $\widetilde{R}_{d}$ should be less than $R_{d}$. If $\widetilde{R}_{d} \geq R_{d}$, the displacement of the SFRS, $\widetilde{R}_{d} R_{o}\left(\Delta_{B}+\Delta_{D}\right)-R_{o} \Delta_{D}$ will be greater than $R_{o} R_{d} \Delta_{B}$ and the ductility capacity of the SFRS will be exceeded. NBC 2015 provides that as an alternative to increasing the design force by using $\widetilde{R}_{d}$ instead of $R_{d}$ according to Equation 13 , the SFRS may be designed to accommodate the increased displacement.

\section{Acknowledgements}

A significant portion of the background material presented in this paper is based on the work of author's colleagues on the Standing Committee on Earthquake Design; their contributions are gratefully acknowledged. Where details of such work have appeared in previous publications, appropriate references have been cited. Some of the details are available only in the internal documents of SCED. Special thanks are extended to John Adams and Gail Atkinson, whose work led to the definition of seismic hazard, to Adrian Wightman and Liam Finn, who developed the site effect factors, to Ron De Vall for developing the provisions related to design in low seismic zones, to Robert Tremblay for his work on flexible diaphragm, to Ken Elwood for his work on inclined columns, and to John Tsertobitoff for his work on base isolation and passive energy dissipating devices. 


\section{References}

Adams, J., Halchuk, S., Allen, T.I., Rogers, G.C. 2015. Canada's $5^{\text {th }}$ generation seismic hazard model, as prepared for the 2015 National Building Code of Canada. The $11^{\text {th }}$ Canadian Conference on Earthquake Engineering, Victoria, BC. Paper No. 93775.

Allen, T.I., Luco, N., Halchuk, S. 2015. Exploring risk-targeted ground motions for the National Building Code of Canada. The $11^{\text {th }}$ Canadian Conference on Earthquake Engineering, Victoria, BC. Paper No. 93781.

Atkinson, G.M. 2009. Earthquake time histories compatible with 2005 National Building Code of Canada Uniform Hazard Spectrum. Canadian Journal of Civil Engineering. 36, 9911000 .

Atkinson, G. M., and J. Adams, 2013. Ground motion prediction equations for application to the 2015 Canadian national seismic hazard maps, Canadian Journal of Civil Engineering. 40, 988-998.

Finn, W.D. Liam, Wightman, A. 2003. Ground motion amplification factors for the proposed 2005 edition of the National Building Code of Canada. Canadian Journal of Civil Engineering. 30, 272-278

Humar, J., and Mahgoub, M.A. 2003. Determination of seismic design forces by the equivalent static load method. Canadian Journal of Civil Engineering 30, 287-307.

Humar, J. and Popovski, M. 2013. Seismic response of single-storey buildings with flexible diaphragms. Canadian Journal of Civil Engineering, 40, 875-886.

Mitchell, D., Tremblay, R., Karacabeyli, E. Paultre, P., Saatcioglu, M., and Anderson, D.L. 2003. Seismic force modification factors for the proposed 2005 edition of the National Building Code of Canada. Canadian Journal of Civil Engineering 30, 308-327.

Tremblay, R., Berair, T., and Filiatrault. 2000. Experimental behaviour of low-rise steel buildings with flexible roof diaphragms. 12th World Conference on Earthquale Engineering. Auckland, NZ. Paper No. 2567.

Tremblay, R. and Stiemer, S.F. 1996. Seismic Behavior of Single-storey Steel Structures with a Flexible Roof Diaphragm. Canadian Journal of Civil Engineering, 23(1): 49-62.

Trudel-Languedoc, S., Tremblay, R., Shrestha, K. and Rogers, C.A. 2012. Seismic force and ductility demand on the braced bents of single-storey buildings with flexible roof deck diaphragms. 15th World Conference on Earthquake Engineering, Lisbon, Portugal 
Table 1: Values of foundation factors as functions of Site Class and $\underline{P G A_{r e f}}$

\begin{tabular}{|c|c|c|c|c|c|}
\hline \multirow{2}{*}{$\begin{array}{c}\text { Site } \\
\text { Class }\end{array}$} & \multicolumn{5}{|c|}{ Values of $F(0.2)$} \\
\hline & $\left.P G A_{\text {ref }}\right) \leq 0.1$ & $\mathrm{PGA}_{\text {ref }}=0.20$ & $\mathrm{PGA}_{\text {ref }}=0.30$ & $P G A_{\text {ref }}=0.40$ & $P G A_{\text {ref }} \geq 0.50$ \\
\hline A & 0.69 & 0.69 & 0.69 & 0.69 & 0.69 \\
\hline B & 0.77 & 0.77 & 0.77 & 0.77 & 0.77 \\
\hline C & 1.00 & 1.00 & 1.00 & 1.00 & 1.00 \\
\hline D & 1.24 & 1.09 & 1.00 & 0.94 & 0.90 \\
\hline \multirow[t]{2}{*}{$E$} & 1.64 & 1.24 & 1.05 & 0.93 & 0.85 \\
\hline & \multicolumn{5}{|c|}{ Values of $F(0.5)$} \\
\hline A & 0.57 & 0.57 & 0.57 & 0.57 & 0.57 \\
\hline B & 0.65 & 0.65 & 0.65 & 0.65 & 0.65 \\
\hline C & 1.00 & 1.00 & 1.00 & 1.00 & 1.00 \\
\hline D & 1.47 & 1.30 & 1.20 & 1.14 & 1.10 \\
\hline \multirow[t]{2}{*}{$E$} & 2.47 & 1.80 & 1.48 & 1.30 & 1.17 \\
\hline & \multicolumn{5}{|c|}{ Values of $F(1.0)$} \\
\hline A & 0.57 & 0.57 & 0.57 & 0.57 & 0.57 \\
\hline B & 0.63 & 0.63 & 0.63 & 0.63 & 0.63 \\
\hline C & 1.00 & 1.00 & 1.00 & 1.00 & 1.00 \\
\hline D & 1.55 & 1.39 & 1.31 & 1.25 & 1.21 \\
\hline \multirow[t]{2}{*}{$E$} & 2.81 & 2.08 & 1.74 & 1.53 & 1.39 \\
\hline & \multicolumn{5}{|c|}{ Values of $F(2.0)$} \\
\hline A & 0.58 & 0.58 & 0.58 & 0.58 & 0.58 \\
\hline B & 0.63 & 0.63 & 0.63 & 0.63 & 0.63 \\
\hline C & 1.00 & 1.00 & 1.00 & 1.00 & 1.00 \\
\hline D & 1.57 & 1.44 & 1.36 & 1.31 & 1.27 \\
\hline \multirow[t]{2}{*}{$E$} & 2.90 & 2.24 & 1.92 & 1.72 & 1.58 \\
\hline & \multicolumn{5}{|c|}{ Values of $F(5.0)$} \\
\hline A & 0.61 & 0.61 & 0.61 & 0.61 & 0.61 \\
\hline B & 0.64 & 0.64 & 0.64 & 0.64 & 0.64 \\
\hline C & 1.00 & 1.00 & 1.00 & 1.00 & 1.00 \\
\hline D & 1.58 & 1.48 & 1.41 & 1.37 & 1.34 \\
\hline \multirow[t]{2}{*}{$E$} & 2.93 & 2.40 & 2.14 & 1.96 & 1.84 \\
\hline & \multicolumn{5}{|c|}{ Values of $F(10.0)$} \\
\hline A & 0.67 & 0.67 & 0.67 & 0.67 & 0.67 \\
\hline B & 0.69 & 0.69 & 0.69 & 0.69 & 0.69 \\
\hline C & 1.00 & 1.00 & 1.00 & 1.00 & 1.00 \\
\hline D & 1.49 & 1.41 & 1.37 & 1.34 & 1.31 \\
\hline$E$ & 2.52 & 2.18 & 2.00 & 1.88 & 1.79 \\
\hline
\end{tabular}


Table 2: Periods and modal weights for different structural types

\begin{tabular}{ccccccc}
\hline $\begin{array}{c}\text { Mode } \\
\text { No. }\end{array}$ & \multicolumn{2}{c}{ Moment frame } & \multicolumn{2}{c}{ Braced frame } & \multicolumn{2}{c}{ Shear wall } \\
\hline Period, s & $\begin{array}{c}\text { Modal } \\
\text { weight, } \%\end{array}$ & Period, s & $\begin{array}{c}\text { Modal } \\
\text { weight, } \%\end{array}$ & Period & $\begin{array}{c}\text { Modal } \\
\text { weight, \% }\end{array}$ \\
\hline 1 & 1.000 & 74.12 & 1.000 & 71.71 & 1.000 & 64.49 \\
\hline 2 & 0.388 & 11.83 & 0.349 & 18.70 & 0.159 & 19.76 \\
\hline 3 & 0.219 & 5.07 & 0.195 & 4.10 & 0.057 & 6.79 \\
\hline 4 & 0.141 & 2.96 & 0.139 & 2.34 & 0.029 & 3.46 \\
\hline 5 & 0.097 & 1.99 & 0.110 & 1.13 & 0.017 & 2.08 \\
\hline 6 & 0.070 & 1.39 & 0.091 & 0.64 & 0.012 & 1.37 \\
\hline 8 & 0.053 & 1.02 & 0.079 & 0.53 & 0.008 & 0.94 \\
\hline 9 & 0.041 & 0.77 & 0.071 & 0.29 & 0.007 & 0.63 \\
\hline 10 & 0.033 & 0.56 & 0.065 & 0.10 & 0.005 & 0.37 \\
\hline & 0.027 & 0.29 & 0.060 & 0.30 & 0.005 & 0.12 \\
\hline
\end{tabular}


Table 3: Spectral ratio for some cities in the western and eastern regions, Class $\mathrm{C}$ soil, for which

\begin{tabular}{lclc}
\multicolumn{2}{c}{ Western region } & & \multicolumn{2}{c}{ Eastern region } \\
\hline \multicolumn{1}{c}{ Location } & $\mathrm{Sa}(\mathbf{0 . 2}) / \mathrm{Sa}(\mathbf{5 . 0})$ & \multicolumn{1}{c}{ Location } & Sa(0.2)/Sa(5.0) \\
\hline Whitehorse & 10.25 & Windsor & 23.23 \\
Inuvik & 12.43 & London & 20.83 \\
Queen Charlotte & 13.13 & Hamilton & 38.20 \\
Prince Rupert & 5.37 & Toronto & 34.97 \\
Tofino & 8.58 & Niagara Falls & 42.44 \\
Campbell River & 6.31 & Kingston & 18.17 \\
Nanaimo & 9.83 & Ottawa & 29.63 \\
Victoria & 10.46 & Montréal & 33.77 \\
Vancouver & 10.55 & Trois-Rivières & 25.46 \\
Prince George & 6.07 & Québec & 28.46 \\
Chilliwack & 8.67 & La-Malbaie & 35.12 \\
Kamloops & 5.07 & Rivière-du-Loup & 36.53 \\
Kelowna & 4.99 & Fredericton & 22.52 \\
Yellowknife & 35.02 & Sept-îles & 31.10 \\
Calgary & 15.44 & Moncton & 20.15 \\
Edmonton & 19.32 & Halifax & 14.57 \\
Winnipeg & 40.85 & Charlottetown & 13.85 \\
& & St. John's & 12.66 \\
\hline
\end{tabular}


Table 4: Spectral ratio for different class of soils for Victoria, Vancouver, Toronto, Montreal

\begin{tabular}{ccccc}
\hline Class & Victoria & Vancouver & Toronto & Montreal \\
\hline Class A & 21.26 & 20.65 & 61.90 & 65.15 \\
Class B & 18.04 & 17.67 & 53.00 & 55.44 \\
Class C & 10.46 & 10.55 & 35.57 & 33.81 \\
Class D & 7.05 & 7.32 & 27.41 & 23.85 \\
Class E & 4.82 & 5.09 & 19.58 & 16.59 \\
\hline
\end{tabular}


Table 5: Higher Mode Factor $M_{V}$ and Base Overturning Reduction Factor $J^{(1)(2)(3)}$

\begin{tabular}{|c|c|c|c|c|c|c|c|c|}
\hline $\begin{array}{l}\mathrm{S}(0.2) l \\
\mathrm{~S}(5.0)\end{array}$ & $\begin{array}{l}M_{v} \text { for } \\
T_{a} \leq 0.5\end{array}$ & $\begin{array}{l}M_{v} \text { for } \\
T_{a}=1.0\end{array}$ & $\begin{array}{c}M_{v} \text { for } \\
T_{a}=2\end{array}$ & $\begin{array}{c}M_{v} \text { for } \\
T_{a} \geq \\
\underline{5.0}\end{array}$ & $\begin{array}{c}\mathrm{J} \text { for } \mathrm{T}_{\mathrm{a}} \\
\leq 0.5\end{array}$ & $\begin{array}{c}J \text { for } \\
T_{a}=1.0\end{array}$ & $\begin{array}{c}J \text { for } \\
T_{a}=2.0\end{array}$ & $\begin{array}{c}\mathrm{J} \text { for } \mathrm{T}_{\mathrm{a}} \\
\geq 5.0\end{array}$ \\
\hline & \multicolumn{8}{|c|}{ Moment-resisting frames } \\
\hline 5 & 1 & 1 & 1 & (4) (5) & 1 & 0.97 & 0.92 & (4) (5) \\
\hline 20 & 1 & 1 & 1 & (4) (5) & 1 & 0.93 & 0.85 & (4) (5) \\
\hline 40 & 1 & 1 & 1 & (4) (5) & 1 & 0.87 & 0.78 & (4) (5) \\
\hline \multirow[t]{2}{*}{65} & 1 & 1 & 1.03 & (4) (5) & 1 & 0.80 & 0.70 & (4) (5) \\
\hline & \multicolumn{8}{|c|}{ Coupled walls ${ }^{(8)}$} \\
\hline 5 & 1 & 1 & 1 & $1^{(6)}$ & 1 & 0.97 & 0.92 & $0.80^{(7)}$ \\
\hline 20 & 1 & 1 & 1 & $1.08^{(6)}$ & 1 & 0.93 & 0.85 & $0.65^{(7)}$ \\
\hline 40 & 1 & 1 & 1 & $1.30^{(6)}$ & 1 & 0.87 & 0.78 & $0.53^{(7)}$ \\
\hline \multirow[t]{2}{*}{65} & 1 & 1 & 1.03 & $1.49^{(6)}$ & 1 & 0.80 & 0.70 & $0.46^{(7)}$ \\
\hline & \multicolumn{8}{|c|}{ Braced frames } \\
\hline 5 & 1 & 1 & 1 & (4) (5) & 1 & 0.95 & 0.89 & (4) (5) \\
\hline 20 & 1 & 1 & 1 & (4) (5) & 1 & 0.85 & 0.78 & (4) (5) \\
\hline 40 & 1 & 1 & 1 & (4) (5) & 1 & 0.79 & 0.70 & (4) (5) \\
\hline \multirow[t]{2}{*}{65} & 1 & 1.04 & 1.07 & (4) (5) & 1 & 0.71 & 0.66 & (4) (5) \\
\hline & \multicolumn{8}{|c|}{ Walls, wall frame systems } \\
\hline 5 & 1 & 1 & 1 & $1.25^{(6)}$ & 1 & 0.97 & 0.85 & $0.55^{(7)}$ \\
\hline 20 & 1 & 1 & 1.18 & $2.30^{(6)}$ & 1 & 0.80 & 0.60 & $0.35^{(7)}$ \\
\hline 40 & 1 & 1.19 & 1.75 & $3.70^{(6)}$ & 1 & 0.63 & 0.46 & $0.28^{(7)}$ \\
\hline \multirow[t]{2}{*}{65} & 1 & 1.55 & 2.25 & $4.65^{(6)}$ & 1 & 0.51 & 0.39 & $0.23^{(7)}$ \\
\hline & \multicolumn{8}{|c|}{ Other systems ${ }^{(9)}$} \\
\hline 5 & 1 & 1 & 1 & (4) (5) & 1 & 0.97 & 0.85 & (4) (5) \\
\hline 20 & 1 & 1 & 1.18 & (4) (5) & 1 & 0.80 & 0.60 & $(4)(5)$ \\
\hline 40 & 1 & 1.19 & 1.75 & (4) (5) & 1 & 0.63 & 0.46 & (4) (5) \\
\hline 65 & 1 & 1.55 & 2.25 & (4) (5) & 1 & 0.51 & 0.39 & $(4)(5)$ \\
\hline
\end{tabular}

\section{Notes to Table 5:}

(1) For intermediate values of the spectral ratio, $M_{V}$ and $J$ shall be obtained by linear interpolation

(2) For intermediate values of the fundamental period, the product $S\left(T_{a}\right) \bullet M_{V}$ shall be obtained by linear interpolation using the $M_{V}$ values obtained as in (1) above

(3) For intermediate values of the fundamental period, J shall obtained by linear interpolation between the $J$ values obtained as in (1) above

(4) Equivalent Static method gives the minimum lateral earthquake force for certain cases.

(5) For fundamental lateral periods, $T_{a}$, greater than $2.0 \mathrm{~s}$, use the 2.0 second values obtained as in (1) above. 
(6) For fundamental lateral periods, $T_{a}$, greater than $4.0 \mathrm{sec}$, use the $4 \mathrm{sec}$ value of $S\left(T_{a}\right) \bullet M_{V}$ obtained by interpolation between $2.0 \mathrm{~s}$. and $5.0 \mathrm{~s}$ using the $M v$ obtained as in (1) above.

(7) For fundamental lateral periods, $T_{a}$, greater than $4.0 \mathrm{sec}$, use the $4 \mathrm{sec}$ value of $J$ obtained by interpolation between $2.0 \mathrm{~s}$. and $5.0 \mathrm{~s}$ using the $J$ obtained as in (1) above.

(8) A "coupled" wall is a wall system with coupling beams, where at least $66 \%$ of the base overturning moment resisted by the wall system is carried by the axial tension and compression forces resulting from shear in the coupling beams.

(9) For hybrid systems, values corresponding to walls must be used or a dynamic analysis must be carried out. 


\section{List of Figures}

Figure 1: Comparison of UHS for NBC 2010 and NBC 2015, both for Class C soil and 5\% damping: (a) Victoria, (b) Vancouver, (c) Toronto, (d) Montreal.

Figure 2: Uniform hazard spectra: (a) Niagara Falls, Toronto, Kingston for Class C soil; (b) Montreal, Ottawa, Trois-Rivières for Class C soil; (c) Victoria for Classes A to E soil; (d) Vancouver for Classes A to E soil.

Figure 3: Uniform hazard spectra for Class C soil and 2/3 cut-off; (a) Tofino, Queen Charlotte City, (b) Victoria, Nanaimo, Campbell River; (c) Chilliwack, Prince George, Vancouver; (d) Charlotte Town, Halifax, St. John's. The dashed lines show 2/3 cut-off.

Figure 4: Comparison of the normalized (with respect to $\mathrm{Sa}(1.0)$ ) spectral accelerations for the first and second modes in moment frame buildings, braced frame buildings and shear wall buildings in Vancouver and Toronto.

Figure 5: $M_{v}$ and $J$ factors: (a) Moment frames, (b) Braced frames, (c) Shear walls.

Figure 6: Relationship between $\kappa$ and $r$ obtained from response history analyses of selected buildings to ground motions compatible to the UHS for Vancouver along with idealized relationships; ductility capacity of brace $\mu=3$. 

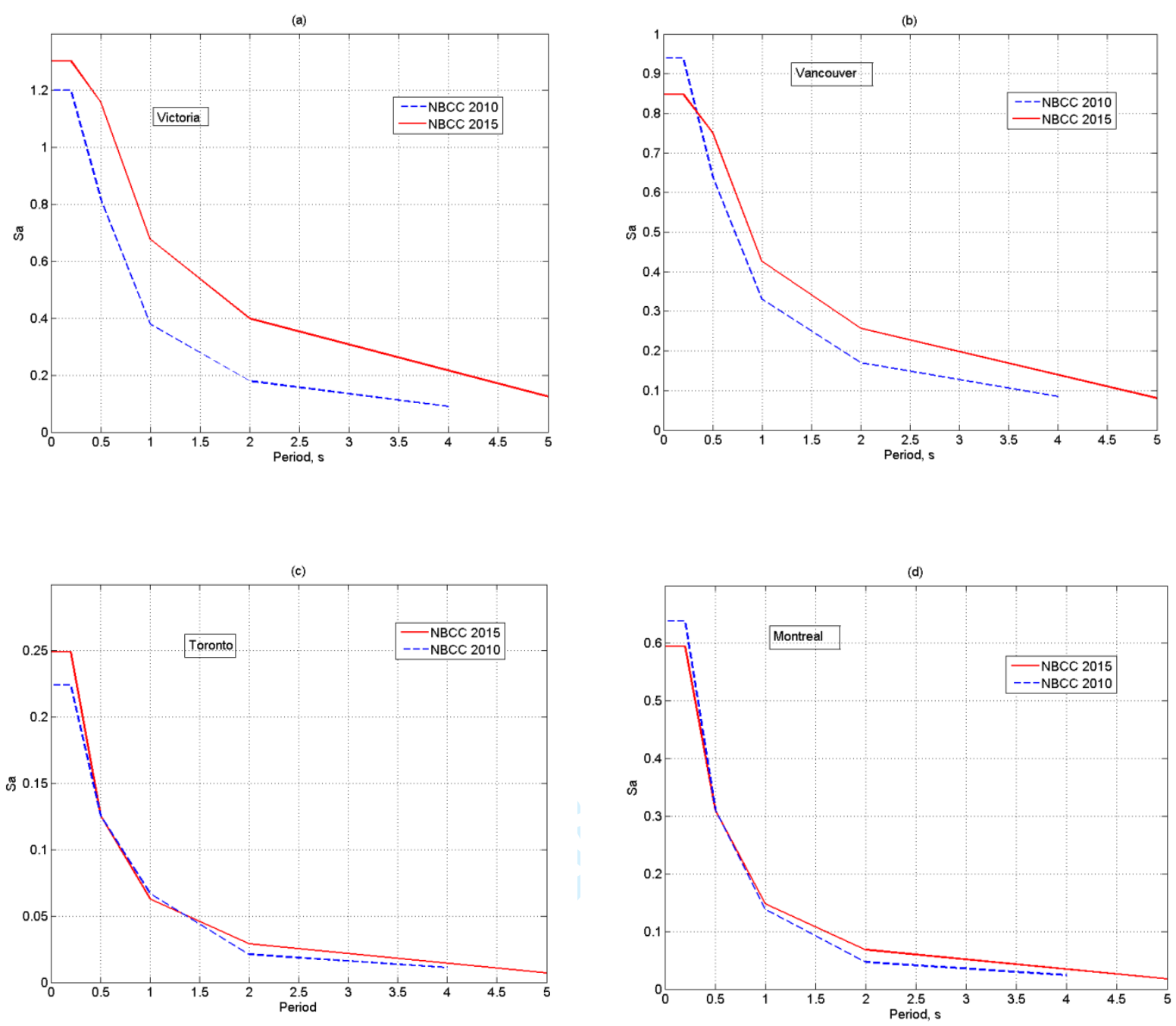


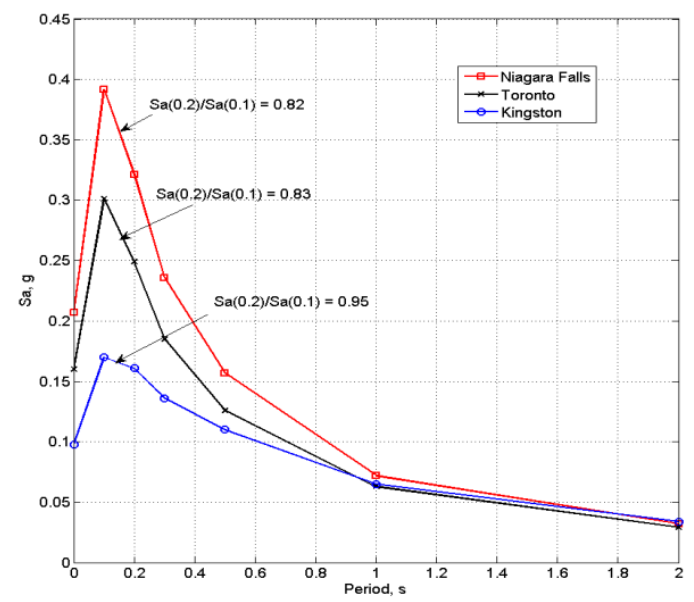

(a)

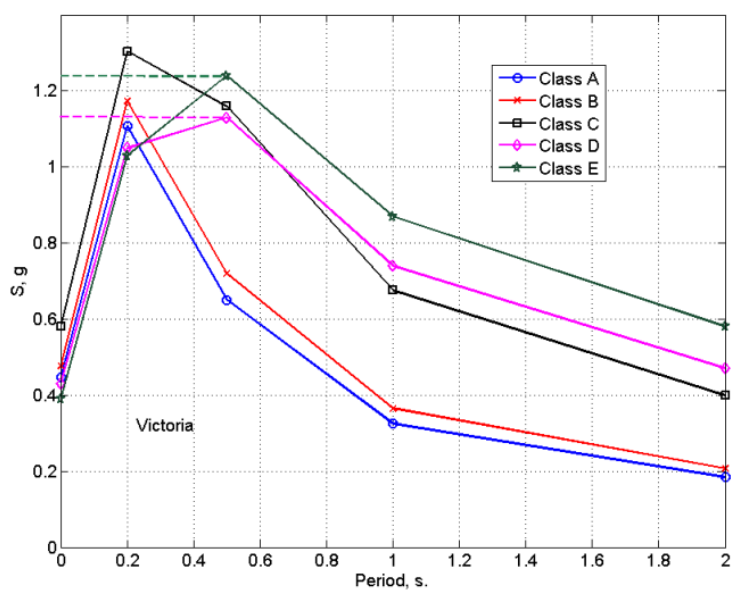

(c)

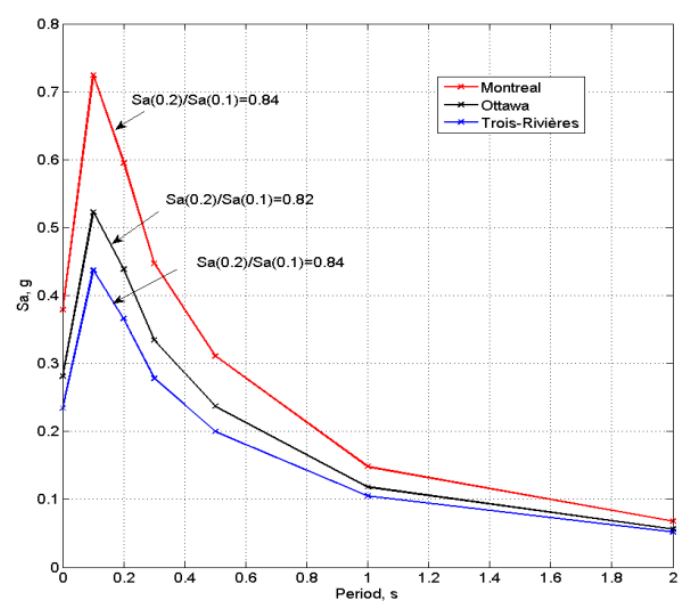

(b)

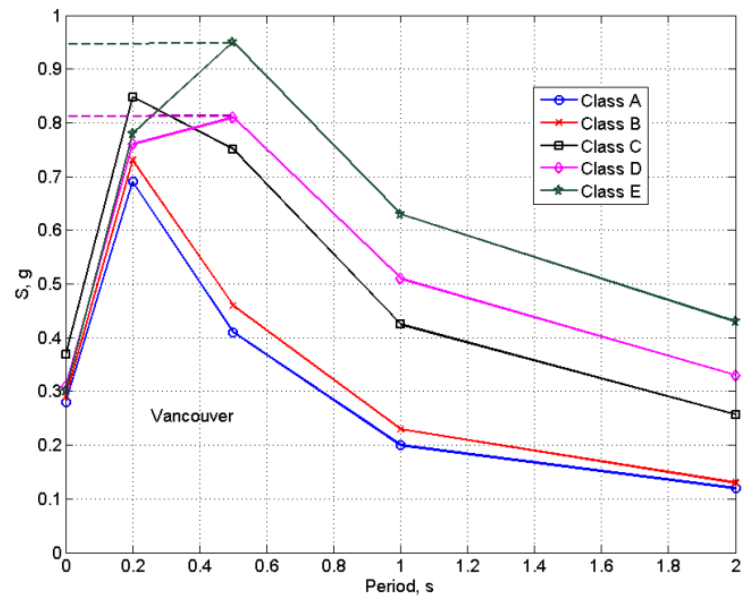

(d) 


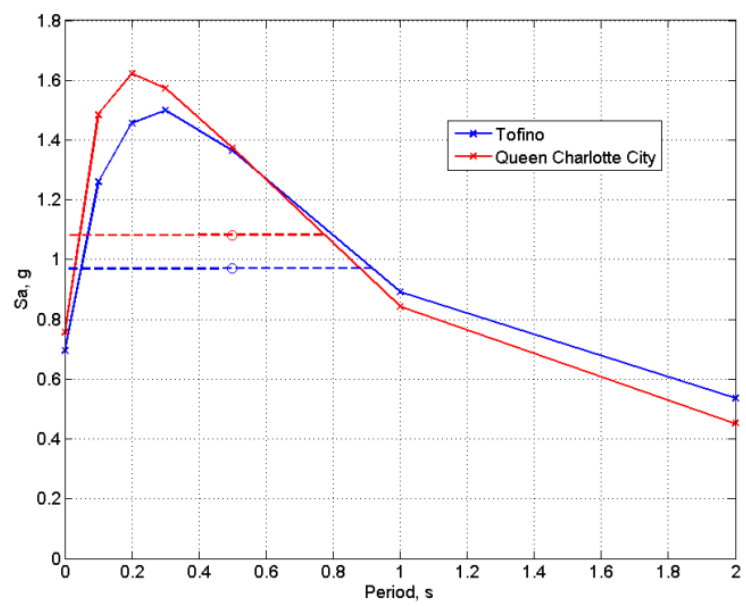

(a)

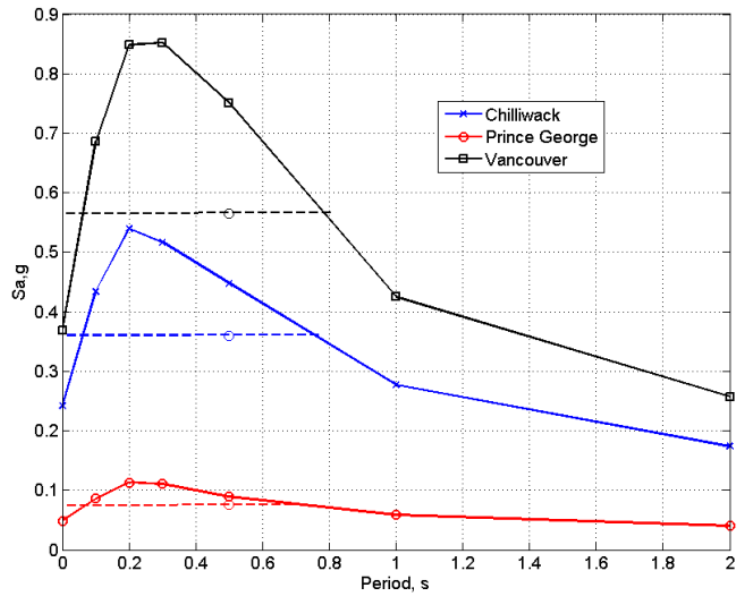

(c)

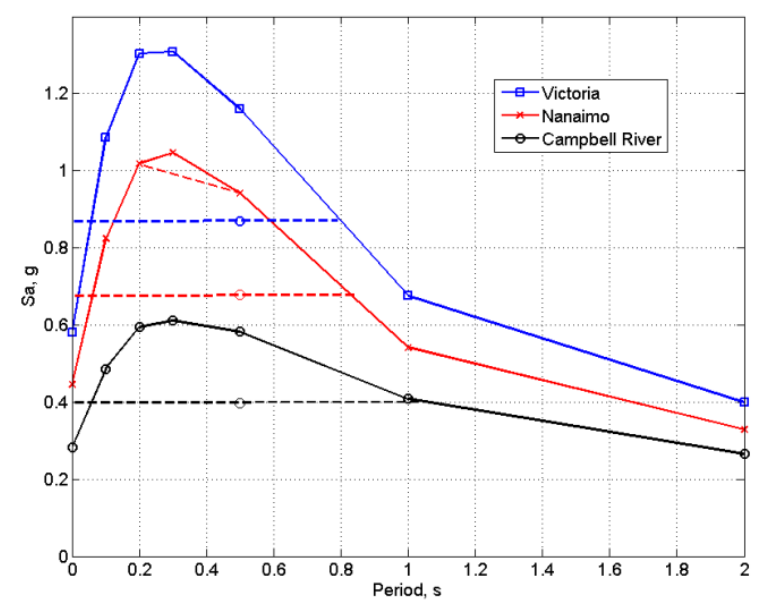

(b)

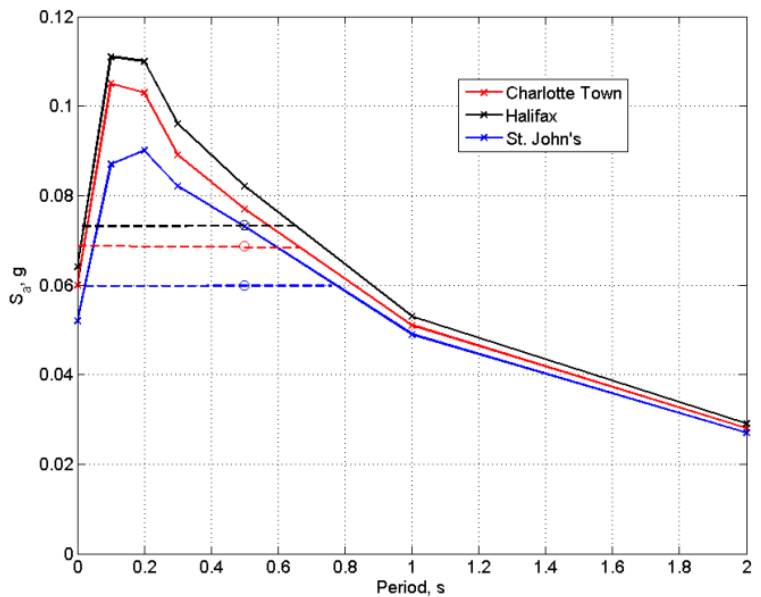

(d) 


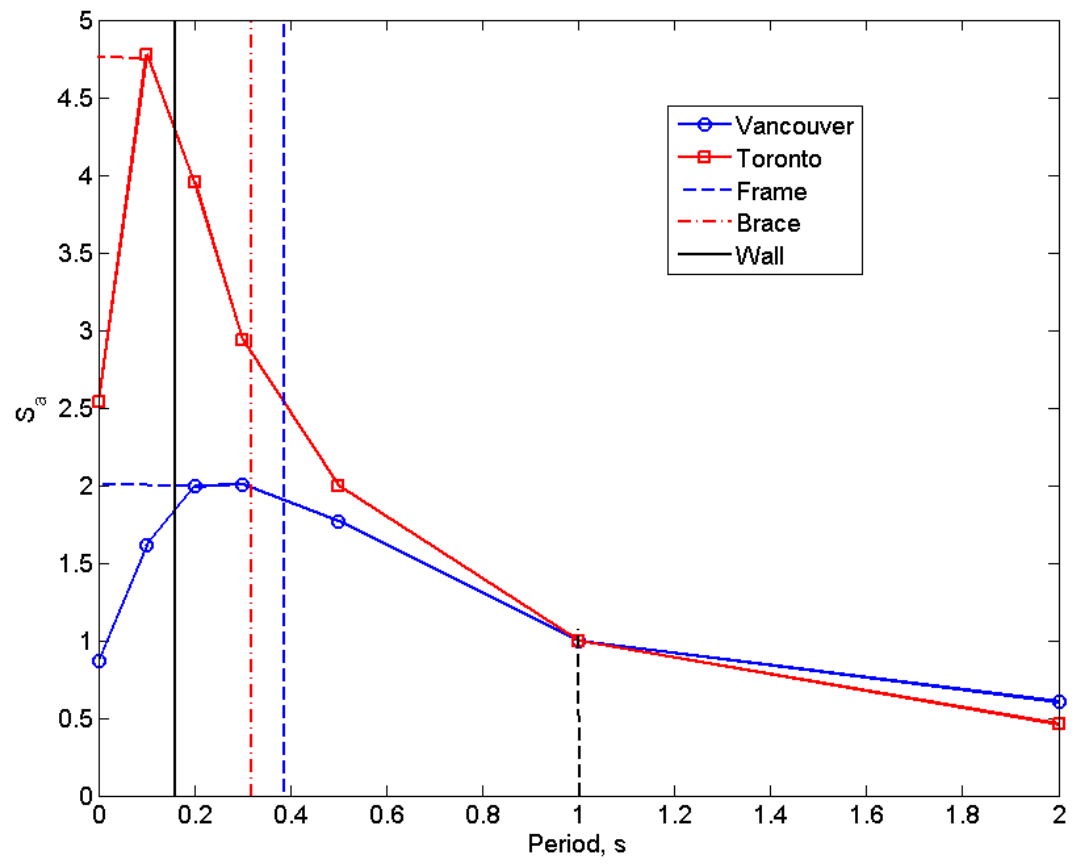

https://mc06.manuscriptcentral.com/cjce-pubs 

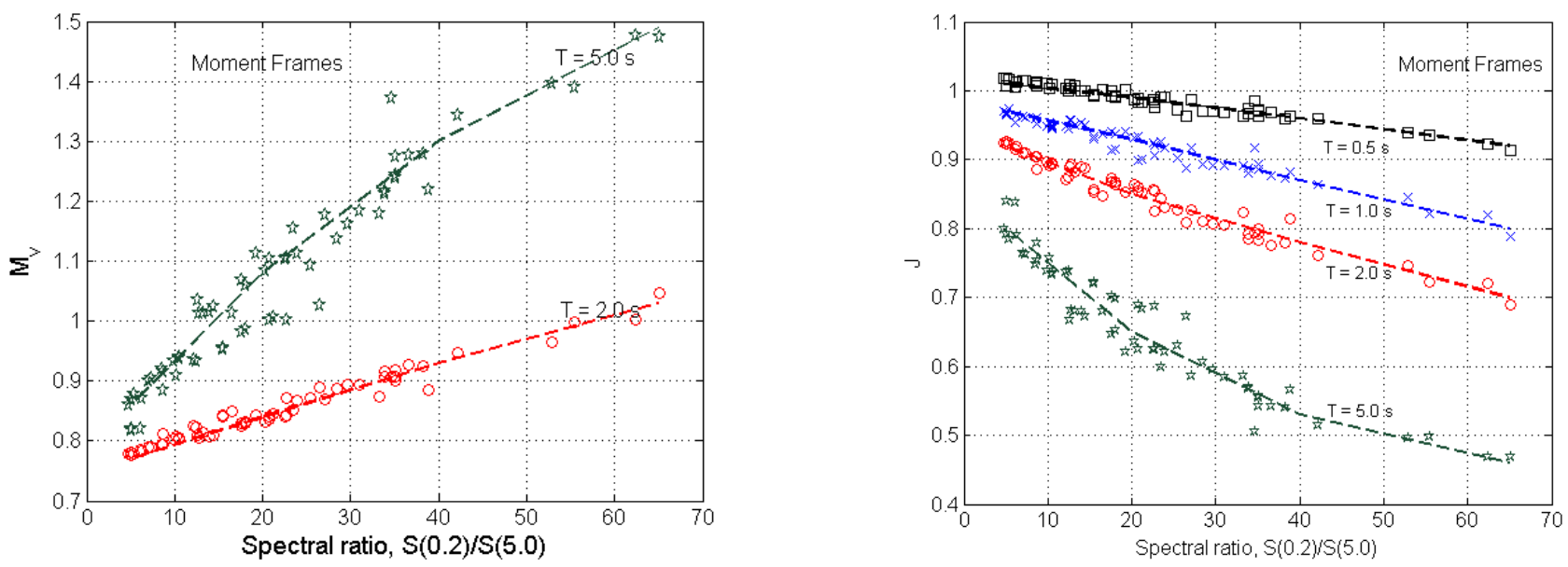

(a)
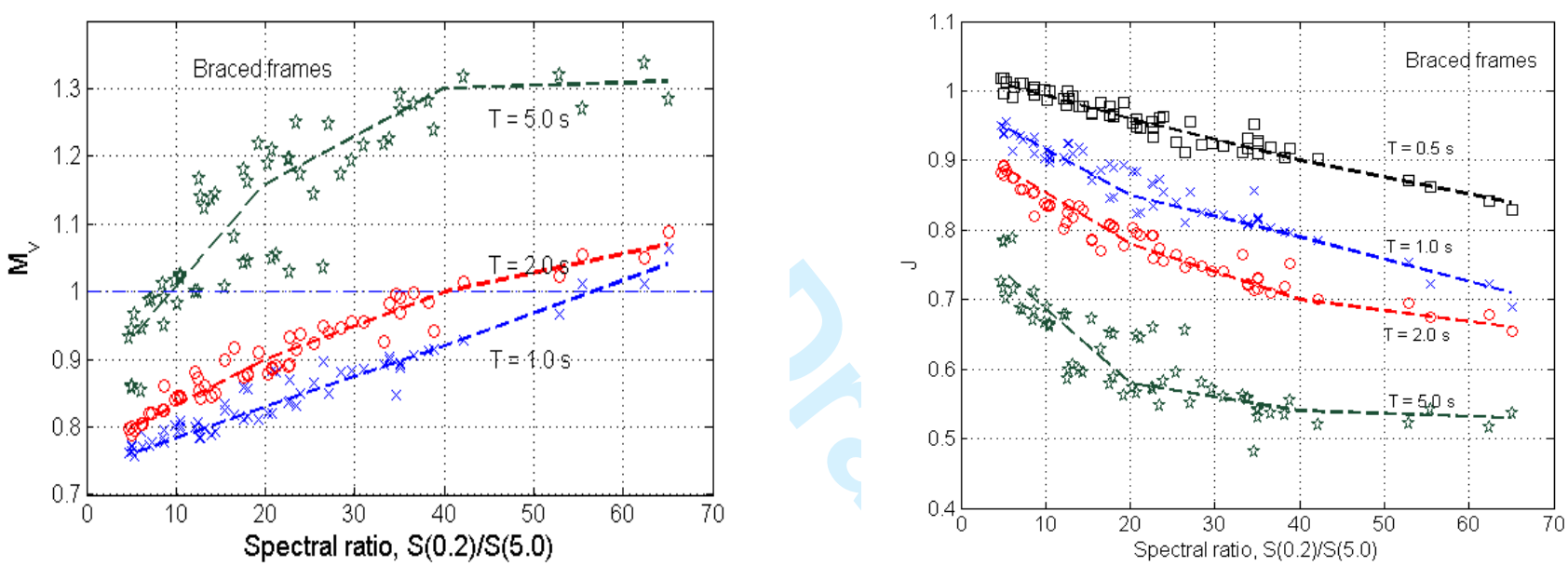

(b)
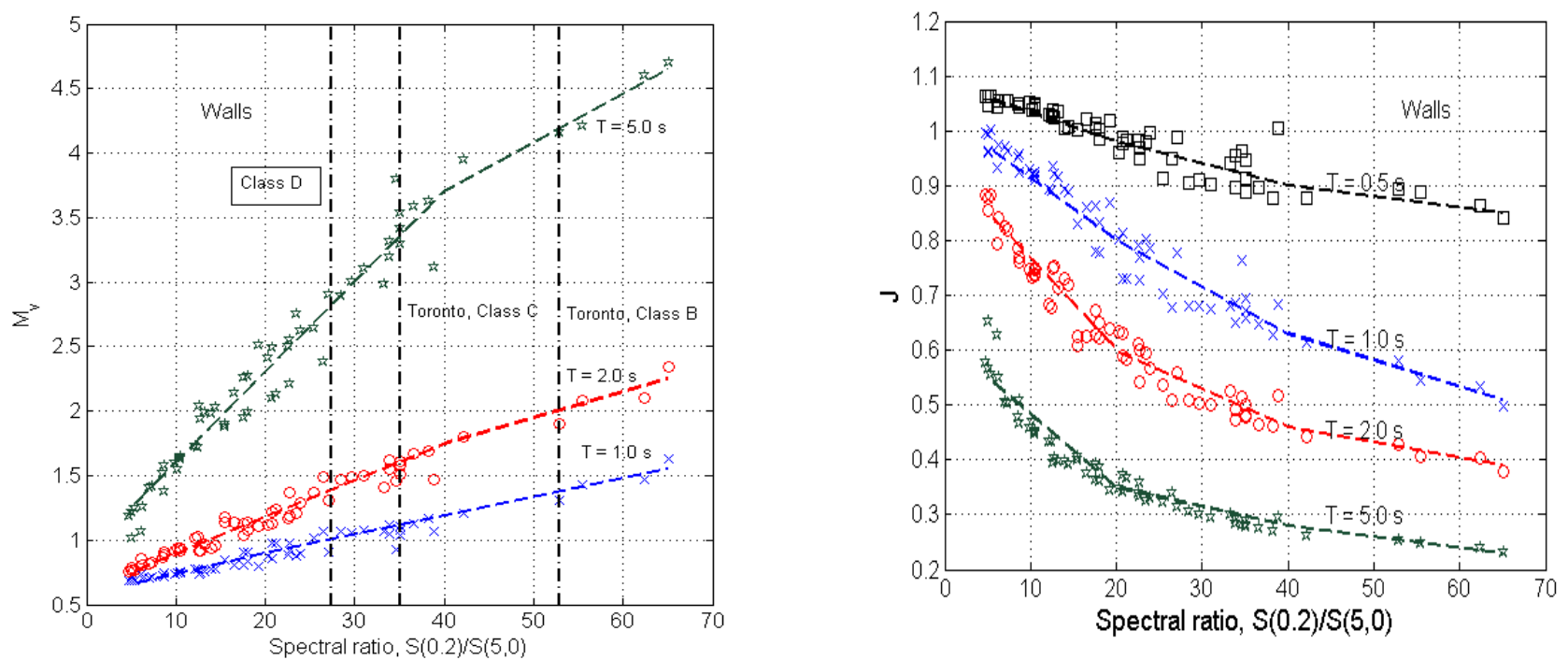

(c) 


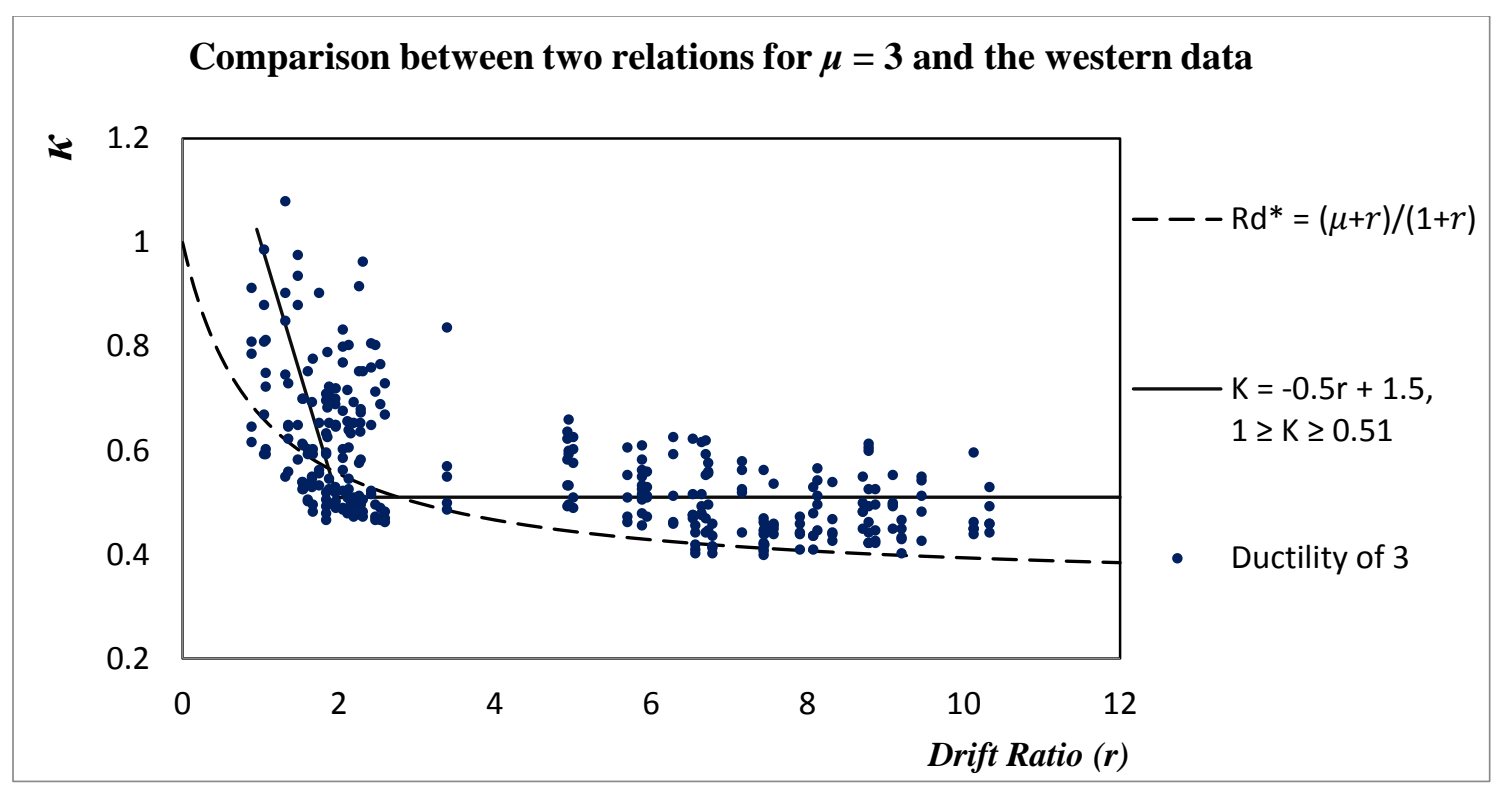

